\title{
COVID-19 among cancer patients. What we know so far?
} COVID-19 entre pacientes com câncer. O que sabemos até agora? Renata D’Alpino Peixoto ${ }^{\circledR}$, Moises de Sousa Martins Lopes².

\begin{abstract}
In December 2019, a novel coronavirus disease (COVID-19) emerged in Wuhan, a city in the Hubei, Province of China. It rapidly spread in an epidemic fashion throughout China, followed by rapid increasing number of cases in many countries throughout the world, including Brazil. It is expected that oncologic patients have an increased risk of COVID-19 infection with possible worse clinical outcomes. We aim at reviewing current evidence of COVID-19 disease among cancer patients.
\end{abstract}

Keywords: Coronavirus; Cancer survivors; Drug therapy.

\begin{abstract}
Em dezembro de 2019, uma nova doença de coronavírus (COVID-19) surgiu em Wuhan, uma cidade na província de Hubei, na China. Esta se espalhou rapidamente de maneira epidêmica por toda a China, seguida por um número crescente de casos em muitos países do mundo, inclusive no Brasil. Espera-se que pacientes oncológicos tenham um risco aumentado de infecção por COVID-19, com possíveis piores resultados clínicos. Nosso objetivo é revisar as evidências atuais da doença de COVID-19 entre pacientes com câncer.
\end{abstract} Keywords: Coronavírus; Sobreviventes de câncer; Terapia medicamentosa. 
In December 2019, a novel coronavirus disease (COVID-19) emerged in Wuhan, a city in the Hubei, Province of China. It rapidly spread in an epidemic fashion throughout China, followed by rapid increasing number of cases in many countries throughout the world, including Brazil.(1) WHO has declared COVID-19, caused by SARS-CoV-2, a public health emergency of international concern. ${ }^{(1)}$

It is well known that cancer patients are more susceptible to infection than the general population due to their systemic immunosuppressive state caused by either the malignancy or anticancer treatments. ${ }^{(2)}$ Therefore, it is expected that oncologic patients have an increased risk of COVID-19 infection with possible worse clinical outcomes. We aim at reviewing current evidence of COVID-19 disease among cancer patients.

The Chinese Center for Disease Control and Prevention published the largest case series of COVID-19 in China $(n=72314))^{(3,4)}$ Most cases $(81 \%)$ were classified as mild, while $14 \%$ were severe (dyspnea, respiratory frequency $\geq 30 / \mathrm{min}$, blood oxygen saturation $\leq 93 \%$, partial pressure of arterial oxygen to fraction of inspired oxygen ratio $<300$, and/or lung infiltrates $>50 \%$ within $24-48$ hours), and $5 \%$ critical (respiratory failure, septic shock, and/or multiple organ dysfunction or failure). ${ }^{(4)}$ The overall case-fatality rate was $2.3 \%$, which increased to $14.8 \%$ among patients aged $\geq 80$ years and $8.0 \%$ among those aged $70-79$ years. In addition, case-fatality rate was elevated among those with preexisting comorbid conditions, including 5.6\% for cancer. ${ }^{(4)}$

Another study including 1099 patients with laboratory-confirmed COVID-19 from 552 hospitals in China evaluated admission rate to intensive care unit (ICU), use of mechanical ventilation (MV), or death as the primary endpoint. (5) Patients with cancer comprised only $0.9 \%$ of all patients $(n=10)$, with $30 \%$ considered as severe. Only one patient satisfied the primary composite endpoint. ${ }^{(5)}$

In parallel, Chinese efforts established a prospective cohort to monitor national COVID-19 cases and analyzed 2007 laboratory-confirmed and admitted cases. $^{(6)}$ After excluding 417 cases with insufficient records, 18 of 1590 COVID-19 cases had a history of cancer. Among those 18 patients, 5 had lung cancer ( 2 on targeted therapy, 2 on chemotherapy and 1 in routine follow-up), 4 colorectal (all on routine followup), 3 breast (all on routine follow-up), 2 bladder (all on routine follow-up), 1 lymphoma (no information available), 1 adrenal (3 weeks after operation), 1 thyroid (on TSH inhibition therapy), and 1 renal cancer (on immunotherapy). Therefore, $75 \%$ of the infected patients were cancer survivors in routine follow-up, who may not be truly immunosuppressed when compared to those on active treatment. ${ }^{(6)}$

Compared with non-cancer patients, oncologic patients were older (mean 63.1 vs 48.7, $p<0.001$ ), more likely to have a history of smoking (22.2 vs 6.8\%, $p=0.032$ ), developed more polypnea (47.1 vs $23.5 \%$, $p=0.039)$, and had more severe baseline computed tomography abnormalities ( 94.4 vs $70.8 \%, p=0.033$ ). Among those cancer patients, $39 \%$ had a severe event (defined as ICU admission, VM, or death) compared to $8 \%$ of non-cancer patients ( $p=0.0003$ ). Other characteristics, such as gender, presence of other comorbidity and abnormalities in X-rays were similar between cancer and non-cancer patients. ${ }^{(6)}$

As expected, patients who underwent active systemic treatment (chemotherapy or immunotherapy) or surgery in the past 30 days had a non-statistically significant higher risk of severe events than others (75 vs 43\%). After logistic regression adjusting for important factors, treatment in the past month was statistically related to severe outcomes (OR 5.34, $95 \% \mathrm{Cl} 1.80-16.18, p=0.0026)$. In this nationwide Chinese study, cancer history was actually the highest risk for developing severe events, which was further increased in older patients (OR 1.43, 95\% $\mathrm{Cl} 0.97-2.12, p=0.072)$. The authors also reported that cancer patients had a median time to severe events of 13 days as compared to 43 days for those without cancer $(p<0.0001)$, indicating a more rapid deterioration. ${ }^{(6)}$

Unfortunately, data on COVID-19 among cancer patients is still scarce with less than 30 described cases. Along with the small sample size of only Chinese patients, there is a large amount of heterogeneity with several cancer types and different oncologic treatments. In addition, cancer cases were not fully described, many of them were already cured with no clear immunosuppression, and many had history of smoking and were older than non-cancer patients, which might explain the worse outcomes.

In conclusion, although cancer patients with COVID-19 are expected to have a poorer outcome, data remains scarce. We are still learning from this outbreak and international collaboration is necessary for better describe the characteristics and outcomes of COVID-19 disease among cancer patients.

\section{REFERENCES}

1. World Health Organization (WHO). Director-General's remarks at the media briefing on 2019nCoV [Internet]. Genebra: WHO; 2020 Feb; [access in 2020 Feb 12]. https://www.who.int/ dg/speeches/detail/who-director-general-s-re- marks-at-the-media-briefing-on-2019-ncov-on11-february-2020

2. Gudiol C, Aguado JM, Carratalà J. Bloodstream infections in patients with solid tumors. Virulence. 2016 Apr;7(3):298-308. 
3. Novel Coronavirus Pneumonia Emergency Response Epidemiology Team. Vital surveillances: the epidemiological characteristics of an outbreak of 2019 novel coronavirus diseases (COVID-19)-China, 2020. China CDC Weekly [Internet]. 2020; [access in 2020 Feb 12]. Available from: http://weekly.chinacdc.cn/en/article/id/ e53946e2-c6c4-41e9-9a9b-fea8db1a8f51

4. Wu Z, McGoogan JM. Characteristics of and important lessons from the coronavirus disease 2019 (COVID-19) outbreak in China. Summary of a report of 72314 cases from the Chinese Center for Disease Control and Prevention. JAMA. 2020 Feb 24; [Epub ahead of print]. DOI: https://doi. org/10.1001/jama.2020.2648
5. Guan WJ, Ni ZY, Hu Y, Liang WH, Ou CQ, He JX, et al. Clinical characteristics of coronavirus disease 2019 in China. N Engl J Med. 2020 Feb 28; [Epub ahead of print]. DOI: https://doi.org/10.1056/NEJMoa2002032

6. Liang W, Guan W, Chen R, Wang W, Li J, Xu K, et al. Cancer patients in SARS-CoV-2 infection: a nationwide analysis in China. Lancet Oncol. 2020 Mar;21(3):335-7. DOI: https://doi.org/10.1016/ S1470-2045(20)30096-6 